This article was downloaded by: [The University of British Columbia]

On: 03 October 2012, At: 10:14

Publisher: Routledge

Informa Ltd Registered in England and Wales Registered Number: 1072954 Registered

office: Mortimer House, 37-41 Mortimer Street, London W1T 3J H, UK

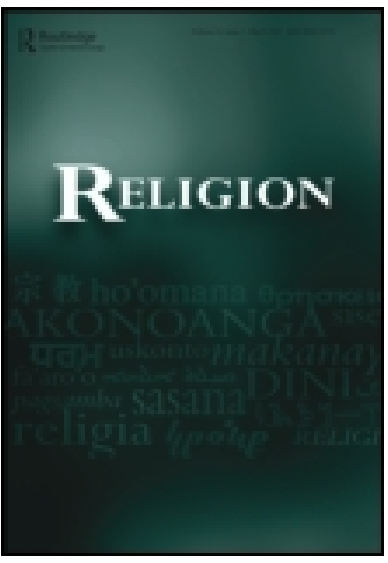

\title{
Religion
}

Publication details, including instructions for authors and subscription information:

http:// www.tandfonline.com/ loi/ rrel20

\section{THE CULTURAL TRANSMISSION OF FAITH Why innate intuitions are necessary, but insufficient, to explain religious belief}

Will M. Gervais, Aiyana K. Willard, Ara Norenzayan \& J oseph Henrich

a University of British Columbia, Department of Psychology, Department of Economics, Canadian Institute for Advanced Research

Version of record first published: 08 Nov 2011.

To cite this article: Will M. Gervais, Aiyana K. Willard, Ara Norenzayan \& J oseph Henrich (2011): THE CULTURAL TRANSMISSION OF FAITH Why innate intuitions are necessary, but insufficient, to explain religious belief, Religion, 41:3, 389-410

To link to this article: http:// dx.doi.org/ 10.1080/ 0048721X.2011.604510

\section{PLEASE SCROLL DOWN FOR ARTICLE}

Full terms and conditions of use: http://www.tandfonline.com/page/terms-andconditions

This article may be used for research, teaching, and private study purposes. Any substantial or systematic reproduction, redistribution, reselling, loan, sub-licensing, systematic supply, or distribution in any form to anyone is expressly forbidden.

The publisher does not give any warranty express or implied or make any representation that the contents will be complete or accurate or up to date. The accuracy of any instructions, formulae, and drug doses should be independently verified with primary sources. The publisher shall not be liable for any loss, actions, claims, proceedings, demand, or costs or damages whatsoever or howsoever caused arising directly or indirectly in connection with or arising out of the use of this material. 


\title{
THE CULTURAL TRANSMISSION OF FAITH
}

\section{Why innate intuitions are necessary, but insufficient, to explain religious belief}

\author{
Will M. Gervais*, Aiyana K. Willard, Ara Norenzayan and Joseph Henrich \\ University of British Columbia, Department of Psychology, Department of Economics, Canadian \\ Institute for Advanced Research
}

\begin{abstract}
The cognitive science of religion integrates insights from diverse scientific disciplines to explain how people acquire, represent and transmit religious concepts. This perspective has led to a fruitful research program on the naturalistic origins of religion. However, it has thus far not directly addressed a key component of religion: faith or committed belief. The present review proposes a framework that integrates standard approaches from the cognitive science of religion with established models of cultural evolution and cultural learning. According to this synthetic approach, innate cognitive content biases explain how people mentally represent gods, and cultural evolutionary models explain why people come to believe and commit to the particular supernatural beliefs that they do. This synthesis offers a more complete picture of the origins and cultural persistence of religious belief.
\end{abstract}

KEY WORDS religion; cultural evolution; cognitive science of religion; atheism; dual inheritance theory

\section{The cultural transmission of faith}

In recent years, researchers from a variety of disciplines have begun to make significant progress in understanding the evolutionary and cognitive origins of religion. One school of evolutionary thought sees religion as a naturally selected genetic adaptation for cooperative group living (e.g., Sosis and Alcorta [2003]; Wade [2009]; Wilson [2003]), while an alternative perspective argues that religion is a natural by-product of normal, everyday psychological processes that evolved for other purposes (e.g., Atran [2002]; Atran and Norenzayan [2004]; Barrett [2004]; Bloom [2007]; Boyer [2001]; Foster and Kokko [2009]; Guthrie [1993]; McCauley [2000]; Pyysiäinen [2001]). In this 'cognitive byproduct' view, we do not have a mind for religion; rather, religion has evolved culturally to fit the minds we have.

Despite the growing influence of the cognitive byproduct perspective, there is considerable room for debate about the role of cultural processes in the evolution

\footnotetext{
*Corresponding author. Email: will@psych.ubc.ca, aiyana@psych.ubc.ca, ara@psych.ubc.ca, henrich@
} psych.ubc.ca 
of religion (see, e.g., Barrett [in press]; Geertz and Markússon [2010]). In particular, one common argument (e.g., Barrett [2004]; Pyysiäinen and Hauser [2010]) is that religious beliefs arise naturally and effortlessly from the biases and tendencies of the human mind, with minimal or no need for extensive cultural scaffolding. This work has led to important insights into the cognitive tendencies and intuitions that bias the human mind towards religiosity and constrain the range of possible religious intuitions across cultures (e.g., Atran and Norenzayan [2004]; Barrett [2000]; Henrich [2009]; Kirkpatrick [1999]; Pyysiäinen and Antonnen [2002]).

In the present paper, we also start from the central argument that religious representations can best be explained as cognitive byproducts of ordinary human thinking. We build on this insight and propose an updated theoretical model that allows for a much greater role than previously assumed for cultural learning processes in shaping and sustaining religious beliefs. We thus situate the cognitive science of religion more firmly within existing frameworks of cultural evolution which emphasize that human thinking and behavior are powerfully shaped both by genetic and cultural inheritance (see e.g., Boyd and Richerson [1985]; Richerson and Boyd [2005]; for related perspectives, see Bulbulia [2008]; Schaller et al. [2010]; Sperber [1996]; Norenzayan and Gervais [in press]). In doing so we invite debate and further research on this relatively neglected topic in the evolutionary study of religion.

The cornerstone of this updated model is twofold: (1) the cultural transmission of concepts - including supernatural religious concepts - are dependent on the cognitive biases that constrain and canalize their content; and (2) these concepts also depend on cultural learning biases that push individuals to selectively attend to and acquire both concepts and degrees of commitment or belief from those around them. We propose that a combination of these two processes has led to the proliferation of certain kinds of religious beliefs, rituals and devotions in the world. We show how this perspective retains the basic insights and explanatory power of the cognitive byproduct perspective, but in addition, address previously unanswered questions about the key distinction between mentally representing supernatural concepts as opposed to believing in them. Take, for example the Mickey Mouse problem, which illustrates that many fictional characters like Mickey Mouse have similar cognitive content as gods, yet are not believed to be real nor committed to the way a god would be (Atran 2002; Atran and Norenzayan 2004). McCauley and Cohen (2010) recently approached this problem by arguing that there is no natural partition between religious and other cultural representations and therefore it may not be clear on what grounds we differentiate them scientifically. We couldn't agree more. Religion is a family-resemblance category, and therefore there is no natural partition between religious and other cultural representations. However, we argue that a significant puzzle remains: scientists need to explain the psychological difference between supernatural beliefs that are mentally represented but treated as fictional (fairies in folk tales, the gods of other religions), and those that are mentally represented and evoke deep worship and commitment (the gods of one's own group). We submit that theories of cultural evolution can explain why some counterintuitive representations galvanize profound commitment, while others are treated merely as entertaining curiosities, despite their transmission advantage. The distinction between mental representation and belief-commitment is crucial to explain cultural differences in the degree of religious commitment around the world, the existence of disbelief, and 
how certain gods, like Zeus - despite having similar cognitive content throughout the ages - can move from a worshiped deity to the fictional character of myths and stories. We thus explain why a supernatural agent with identical content and supported by exactly the same cognitive biases can in one place or time be an idol of immense devotion, while in a different time or place can be merely myth or fanciful tale: this is the so-called 'Zeus Problem' (Gervais and Henrich 2010).

\section{The evolution of cultural learning}

Imagine that tomorrow morning you wake in a strange and novel environment, surrounded by strange people, flora and fauna. Your stomach rumbles hungrily, and you decide to rustle up some breakfast. How would you decide what is safe to eat? You may notice that a lot of people are gathering small brown nuts from a local bush. That is a good sign: if lots of people are interested in these nuts, there's a good chance that they are good to eat. On the other hand, you notice some people gathering mushrooms instead. However, many of the people gathering nuts are obviously successful, while the mushroom gatherers look to be struggling. The nut gatherers are healthy, strong and others look to them for guidance. Finally, you notice that these fit individuals are actually eating the brown nuts. In this rather speculative example, you (a naïve cultural learner) are faced with the question of what to believe about a new environment. Should you believe that nuts are delicious and nutritious, should you believe that mushrooms are preferable, or should you instead set out on your own and begin trying various foods for yourself?

This anecdote illustrates a fundamental point about how humans come to commit to certain beliefs. Although social learning can be found in many animal species (e.g., Whiten [2005]), humans rely upon each other for adaptive information to an unparalleled degree in the animal kingdom. Unlike other animals, humans - even foragers - cannot survive without tapping the vast reserves of accumulated cultural knowledge about finding food, making shelters, cooking and producing tools. As a consequence, our species is addicted to culture, and the vast bulk of preferences, motivations, attitudes and beliefs are - or can be - influenced by transmission from other members of their social group (Henrich and McElreath 2003). We argue that a scientific understanding of the origins of religious faith would be incomplete without considering this critical dependence on others as sources of information. Below we discuss cultural learning biases and empirical evidence for them in more detail. We then explain how these cultural learning biases shed important light on the cultural spread and stability of religious beliefs and practices.

Because humans depend on others for information, they must be sensitive to the quality of the information they acquire from different sources. Some cultural evolutionary theories (e.g., Henrich and McElreath [2003]; Richerson and Boyd [2005]) recognize two broad types of psychological mechanisms that aid in the processing of such information, termed representational content biases and context biases (or model-based learning biases), respectively. When using content biases, humans selectively retain some information because of differences in the actual content of information. Some types of information are easier to remember, more emotionally evocative (fitness relevant), or allow more potent inferences to be made about the surrounding world. Concepts supported by these content biases would hold privileged status in cultural transmission. Content biases have been the primary 
focus of much of the previous work in the understanding of the cognitive origins of religion, while context biases have received little attention (Henrich 2009). Though there are several other relevant perspectives on the processes of cultural evolution (see, e.g., Donald [2001]; Sperber [1996]; Tomasello [1999]), and important nuances and distinctions, a complete overview and detailed comparisons is beyond the scope of this paper. Instead we focus on these cultural learning biases within the framework of cultural evolution to explain the transmission of religious belief.

The adaptive value of context learning biases is evident in the above food example. One strategy is for cultural learners to weight how common various beliefs appear to be in their immediate cultural context. If a naïve cultural learner places weight on the prevalence of a certain belief (say, by noticing that most people gather nuts rather than mushrooms), that learner is utilizing a conformist learning bias (Boyd and Richerson 1985; Henrich and Boyd 1998; Kendal, Giraldaeu and Laland 2009). A second strategy is to preferentially imitate cultural models who are older, skilled, prestigious and successful (e.g., Gil-White and Henrich [2001]), often referred to as a prestige-based learning bias.

A third context bias springs from the need for cultural learners to avoid deception. An unscrupulous model might knowingly transmit false information to others, perhaps to maintain a competitive advantage. In this case, it is important for learners to ensure that their models actually hold the beliefs they espouse before adopting the belief themselves. Actions speak louder than words: they are great cues of another's underlying beliefs. For example, if a model who praises mushrooms actually eats the mushrooms, a learner can be more certain that the model holds the belief 'mushrooms are delicious and nutritious' rather than the belief 'mushrooms are toxic.' Alternatively, if a model praises mushrooms but refuses to eat them, the learner would be wise to treat this claim as dubious. In this example, eating the mushrooms constitutes a credibility-enhancing display (CRED) of the model's underlying beliefs regarding mushrooms (Henrich 2009). If models engage in behaviors that would be costly if opposing beliefs were held (that is, if they engage in credibility-enhancing displays of their beliefs) learners can be more confident that the model actually holds the belief, and as a result they would be more receptive to these beliefs (Henrich 2009). In all three strategies (conformist, prestige-based and CREDs) people rely not only on the content of information (in the above example, what a learner already knows about nuts or mushrooms), but also on the context in which learning occurs, that is, various factors relating to a potential cultural model or models that affect the transmittability of a belief.

In this view, learners are expected to utilize a variety of cues to assess which potential information sources are more reliable, and come to preferentially believe information from these sources. The capacities for context-dependent learning emerge early in development. Three- and four-year-old children are more likely to believe information that comes from sources who have proven to be reliable; they prefer sources with a track record of accuracy (e.g., Koenig and Harris [2005]; Koenig, Clément and Harris [2004]; Pasquini et al. [2007]). Children are able to monitor and track the reliability of different sources, using this information to preferentially learn from previously accurate sources of information (Birch, Vauthier and Bloom 2008). Children as young as four preferentially believe information from sources who claim certainty (Sabbagh and Baldwin 2001), or who appear more confident in their information (Birch, Akmal and Frampton in 
press). Children also appear to value experienced sources. When choosing whether to imitate a previously reliable adult source or a previously reliable child source, kids follow the adult (Jaswal and Neely 2007). Recent work shows that young children readily track the visual attention of others (a 'prestige cue') and selectively learn from those who were previously preferentially attended to, even under novel circumstances and in the absence of observers (Chudek et al. 2010).

We next argue that content and context biases interact to affect the spread of certain kinds of religious beliefs. They influence the transmission of religion in different, but complementary, ways. We expect, as has been argued before, that content biases make some concepts inherently more interesting, memorable and transmittable. However, people should also be endowed with capacities for filtering concepts that have dubious credibility, and therefore context biases should be instrumental in explaining patterns of belief in various concepts. More specifically, we argue that content biases affect the potential of a concept to become memorable and contagious, but people will only come to believe in those salient concepts that are supported by appropriate context biases that allow people to selectively acquire cultural information.

Content biases: counterintuition and the cognitive science of religion

Evolutionary approaches to cultural transmission provide a rich set of cognitively informed hypotheses regarding how the content of representations influences their transmission (Boyd and Richerson 1985: 5; Sperber 1996). Specifically, cultural learners should be more likely to pay attention to, store and transmit representations when these are judged more: (1) potentially actionable; (2) fitness relevant and thus emotionally evocative; and (3) plausible or compatible:

(1) 'Potentially actionable' means that the content of a representation leads to inferences that can readily influence subsequent actions, including additional inferences (Inferential Potential: Boyer 2001). Representations, for example, in which the causes of unpleasant circumstances (e.g., storms or illnesses) are random with respect to the actions of those afflicted do not lead to useful or helpful inferences or actions, and thus are not easy to maintain. Evolutionarily non-actionable representations need not be stored because they cannot be of help even if one remembers them. Instead, representations that involve believing that illnesses are caused by the jealously of others (e.g., the 'evil eye') can lead to inferences about who might be causing a particular illness and how one can avoid such illnesses in the future.

(2) 'Fitness relevant': natural selection should favor more attention and recall for representational content of greater relevance to fitness, at least in ancestral environments. Often such content sparks more positive or negative emotional responses, thus adaptively biasing memory storage and recall. People should tend to devote more cognitive resources to stimuli that evoke affective reactions such as disgust, fear, etc., potentially leading to biases in cultural evolution (e.g., Boyer and Lienard [2006]).

(3) 'Plausible or Compatible' representations involve a variety of expectations that a learner might have about how the world works and, consequently, what is more and less likely to be true. Some expectations rely heavily on our reliably developing intuitions, including core cognitive processes related to such domains as mechanics and biology (Spelke and Kinzler 2007). For example, representations from modern physics, which involve objects (e.g., electrons) 
that exist only probabilistically at any point in space, radically violate our intuitive expectations from folk mechanics and thus do not readily transmit. Such plausible or compatible content biases can also be culturally acquired, such that the possession of one mental representation biases the acquisition of others. That is, having acquired a particular idea via cultural transmission, a learner may be more likely to acquire another idea, because the two 'fit together' in some cognitive or psychological sense. For example, believing that performing a certain ritual in the spring will increase the crop harvest in the summer might favor the acquisition of a belief that a similar ritual will increase a woman's odds of conception, a healthy pregnancy and the successful delivery of a robust infant.

Researchers working in the cognitive science of religion have largely focused on these types of content biases to explain the cognitive structure and cultural spread of religious beliefs. This view is already well elaborated and has led to fruitful theorizing and empirical research (e.g., Barrett [2004]; Boyer [2003]; Pyysiäinen and Antonnen [2002]). Here we discuss one influential hypothesis: that the presence of mildly counter-intuitive content in concepts or narratives can bias memory in a manner that would favor such concepts or narratives in cultural evolution (e.g., Barrett and Nyhof [2001]). Counter-intuitive concepts violate our core assumption about the nature of things in the world; usually these assumptions focus on intentional beings, animals, inanimate objects or events (expectations often associated with the cognition domains of folkphysics, folkpsychology and folkbiology). By departing systematically, but mildly, from established cognitive rules we use to understand and organize information in our environment, they achieve greater memorability. Examples of counter-intuitive concepts from this literature are 'a person who can be in two places at once' (Boyer and Ramble 2001) and a 'thirsty door' (Norenzayan et al. 2006). Furthermore, the presence of a few counterintuitive concepts in a narrative, even within a list of otherwise ordinary concepts, improves memory for the entire narrative or list, increasing the transmission advantage of the entire narrative (Norenzayan et al. 2006).

From the perspective just presented, many counter-intuitive concepts probably create complex mixtures of plausibility, applicability and emotional evocativeness. Many religious beliefs, for example, would appear to be more applicable, more emotionally evocative, but less plausible than alternative non-religious concepts or explanations. If counter-intuitive concepts, by their very nature, make stories or beings seem less plausible (less believable), the optimal number of such violations should be small. In an analysis comparing a sampling of successful and unsuccessful Grimm's fairy tales, successful (widely known) fairly tales had only two or three counter-intuitive violations (Norenzayan et al. 2006). Successful counter-intuitive representations are also likely to generate emotional responses, like fear or interest, as well as actionable options and additional inferences.

Researchers have long recognized that representational content biases may play an important role in religious belief. The supernatural agents endemic to religions appear to possess a particularly evocative set of abilities (flight, omniscience or transubstantiation) and characteristics (being invisible or wholly incorporeal) not shared by more mundane agents. People find this minimal counterintuitiveness memorable, giving these concepts a strategic advantage in cultural transmission: they should be more likely to spread and persist. To be culturally successful, 
these deviations must be systematic but not radical departures from common sense as to rupture meaning completely. As Sperber (1996: 73) has put it, these minimal counterintuitions are 'relevant mysteries,' in the sense that they are closely connected to background knowledge, but do not admit to a final interpretation. As a result they are attention arresting and inferentially rich, and therefore encourage further cognitive processing and multiple interpretations over time that facilitate transmission.

The picture we have painted so far explains why religious concepts the world over tend to have the peculiar cognitive structure that they do (e.g., containing a few minimally counterintuitive elements), and why such structure is memorable and contagious. However, it is a far step from memorability and mental representation to sincere belief in and passionate commitment to religious concepts. People believe in only a small subset of the minimally counterintuitive agents that are worshipped around the world, which are themselves but a small subset of all minimally counterintuitive concepts. Furthermore, if these cognitive biases operating on representational content are sufficient to explain the persistence of religious beliefs, why do people come to believe in only a small subset of supernatural agent concepts, when so many concepts share the same or similar content conducive to cultural success?

\section{Can content biases alone explain faith?}

While content biases appear to influence the mental representation, memorability and social contagion of supernatural concepts, they may have difficulty explaining why people come to devoutly commit to the particular supernatural concepts that are prevalent in their own culture. Why do Christians passionately believe in Jesus but not in Shiva (or vice versa for Hindus)? And why is it that Zeus, who has all the cognitive elements necessary to be a successful god, has lost his spell and is no longer a worshipped deity? In other words, can content biases (including the mnemonic advantage of counterintuitive concepts) alone explain patterns of belief and disbelief in supernatural agents?

In a humorous piece titled 'Why Santa Claus Is Not a God,' Barrett (2008) recently attempted a solution to this puzzle of belief, relying on further refinements of content biases. However, we are skeptical that content biases alone can solve the aforementioned puzzles. (For a detailed critique, see Gervais and Henrich [2010]). Cultural learners are not mere passive receptacles who believe in and commit to any concept that is memorable and widespread. (See Bergstrom, Mehlmann and Boyer [2006] for a similar point). Indeed, there are good reasons to suspect skepticism or epistemic vigilance (Sperber et al. 2010) on behalf of cultural learners, even in children. Given both the imperfection of cultural transmission and the threat of manipulation from unscrupulous sources (Henrich 2009), a degree of incredulity is warranted when evaluating new sources and types of cultural information. Consistent with this, children show a sophisticated understanding of the difference between reality and fictional concepts, and perhaps even some inherent resistance to belief in counterintuitive concepts (see, e.g., Bergstrom et al. [2006]; Harris and Koenig [2006]).

Decades of developmental research in psychology support the notion that children appreciate the difference between real entities and fictional entities (e.g., Sharon and Wooley [2004]). They can reliably tell which types of things actually 
exist from those that only exist in pretense (e.g., DiLalla and Watson [1988]; Golomb and Galasso [1995]; Harris et al. [1991]; Morison and Gardner [1978]; Samuels and Taylor [1994]). They can even reason about how fictional agents in one fantasy context might view fictional agents in another fantasy context; they report, for example, that Batman would think that Spongebob is fictional, even though both are fictional characters (Skolnick and Bloom [2006]). Children readily engage in pretend play, without confusing pretense and reality (e.g., Golumb and Kuersten [1996]; Woolley and Wellman [1990]). Many children even entertain imaginary friends, but they still appreciate that these companions are not, in fact, real (Taylor [1999]).

Children are also sensitive to the different types of information they could acquire, even from a reliable source. Older children (eight to nine years old) distinguish between facts and opinions, showing a greater degree of conformity to others' views of factual matters than to others' opinions (Banerjee et al. 2007). As children age, they become increasingly aware that others may systematically distort information. Ten- and 11- year olds are skeptical of self-reports as accurate information about valued personality characteristics such as intelligence (Heyman and Legare 2005). Children recognize that others might misrepresent the world. The development of children's abilities to think critically about sources of information and the types of information for which they might be reliable demonstrates that cultural learners might rely more or less heavily on different context biases for different types of information. (See Heyman [2008].)

Children are able to both easily reason about the difference between reality and fiction and also to mentally represent fictional counterintuitive agents. To complicate matters even further, there is some evidence that children are actually quite skeptical of concepts that violate their intuitive expectations about the world. Mead's (1932) classic study of animism on the island of Manus in New Guinea revealed that children do not readily commit to and believe in the counterintuitive concepts they hear expressed by adults. Rather, the children were somewhat resistant to adopting such concepts. Although controversy surrounds Mead's work, similar patterns emerge from laboratory experiments that generally show that children are more inclined to believe in intuitive concepts over counterintuitive concepts (Harris and Koenig 2006; Harris et al. 2006). In one study, Harris and colleagues (2006) asked children whether they thought a variety of different entities exist. The children reported that a variety of empirically non-verifiable scientific entities such as germs exist, and asserted the existence of endorsed beings like Santa Claus. Although this appears to indicate that the children came to believe in counterintuitive agents like Santa Claus, children were more confident that scientific entities exist than that endorsed beings exist. These authors argue that children might in part be more skeptical of the endorsed beings simply because these beings violate intuitive expectations, leading the children to 'conclude that the existence of special beings such as God or Santa Claus is more dubious than that of scientific entities' (Harris et al. 2006: 92).

This resistance to belief in counterintuitive concepts persists into adulthood. Although university students rate minimally counterintuitive concepts as more supernatural (Atran and Norenzayan 2004), they also rate them to be less believable than intuitive concepts (Willard et al. 2010). Furthermore, Bloom and Weisberg (2007) argue that adult scientific illiteracy stems in part from a resistance to believing things that contradict domain-specific intuitions. For example, in one experiment 
(McKloskey, Caramazza and Green 1980) Johns Hopkins undergraduates - many of whom had taken college physics - were asked to predict the trajectories of objects leaving curved tubes. Consistent with folk physics, and inconsistent with actual physics, most participants guessed that the balls would have curved trajectories. In a variety of domains, children and adults alike have a hard time believing in concepts that violate intuitive expectations about the world.

In sum, content biases make some counterintuitive concepts memorable and, therefore, widespread. However, cultural learners are easily able to remember, represent and reason about concepts without necessarily believing in them. Furthermore, some evidence suggests that people actually resist belief in concepts that routinely violate intuitive expectations. This skepticism of counterintuitive concepts poses a serious challenge for any model of religion that relies exclusively upon representational content biases, as the very same feature (minimal counterintuitiveness) that has been argued to cause religious concepts to spread and persist in cultures may also make the concepts less believable. Content biases therefore appear better able to explain why folktales and myths - that is, stories containing some counterintuitive elements that people do not actually believe to be true - are widespread and memorable than they are able to explain the fact that around the world most people who have ever lived sincerely believe in and commit to only the small subset of counterintuitive supernatural agents popularly endorsed within their own cultural context.

\section{Religious faith in cultural context}

If content biases are insufficient to explain which sorts of religious beliefs people commit to, how might context biases shed further light on religious beliefs? Content biases make supernatural concepts interesting, memorable and contagious, but context biases explain why people come to believe in a particular subset of the supernatural concepts to which people are exposed (Atran and Henrich 2010; Gervais and Henrich 2010). Most people adopt the religious beliefs of their parents and surrounding communities, rather than coming to believe in every memorable or attention-grabbing supernatural agent to which they are exposed. If most of the people in a learner's environment - and especially if the most successful people in the area - say that Zeus throws lightning bolts, or that Yahweh will judge people for their sins, it is likely that the learner will come to believe these propositions, just as the learner will come to adopt the styles of dress or cuisine also demonstrated by the rest of the community. Furthermore, most religions give believers ample opportunity to exhibit credibility-enhancing displays of their fealty to a given god - public prayer, painful rites of passage, martyrdom - that will further ratchet up belief in cultural learners. (See Henrich [2009] for a comprehensive treatment). Although the content of many supernatural agent concepts make them likely god candidates, people tend to actually believe in only the supernatural concepts supported by context biases.

Context biases make obvious many features of religion that are unexplainable by content biases alone. Context biases can help explain patterns in people's beliefs about the origins of species, beliefs about death and patterns of belief and disbelief in various supernatural agents (across societies and within individual lifespans). Importantly, some noted researchers (e.g., Barrett [in press]) have made strong claims that supernatural beliefs in each of these domains emerge naturally, with 
little or no cultural scaffolding. However, upon close examination, the limited available evidence regarding these claims is fragmentary and often inconsistent. In the three next sub-sections, we treat each of these domains as a case study in which to explore the main prediction made by a cognitive byproduct perspective that is informed by context biases: that supernatural concepts have predictable cognitive structure that make them memorable and contagious, but people come to believe only in the narrow subset of those supernatural concepts supported by context biases and credibility enhancing displays within their immediate social context.

\section{Children's reasoning about animal origins}

If some elements of religion emerge naturally and require little or no cultural scaffolding, some form of theistic belief should be clearly present in young children who have not yet been exposed to the cultural ideas that could modify these core religious tendencies. Children's beliefs about the origins of species are often cited as evidence that some forms of supernatural beliefs are cognitive defaults that are merely filled in by - rather than substantially influenced by - cultural contexts. Children might be intuitive creationists, predisposed to believe that animals were created by some supernatural agent. They could fill in this blank with whatever supernatural agent they find particularly memorable and interesting. Children's intuitions about the origins of species, then, may be crucial to an understanding of how supernatural beliefs are acquired.

Are children intuitive creationists, invoking the existence of supernatural agents to explain the origins of species? Children in general tend to prefer teleological explanations for things, liberally inferring function and purpose (Kelemen 2004). Thus clouds do not just rain, they are for raining. This 'promiscuous teleology' has been argued to indicate that viewing nature as inherently intentional is a default cognitive position. We find this hypothesis plausible, although we note that there is as yet no direct experimental evidence that teleological thinking causes inferences of a supernatural agent behind the purpose in nature - a possibility that merits direct research.

In an empirical test of children's beliefs about animal origins, Evans (2000) asked children about where new types of animals come from in order to assess the degree to which they use evolutionary and creationist concepts in their biological reasoning. The youngest children (roughly age seven) in this experiment were unsystematic in their responses, claiming that new species spontaneously appear, evolve or are products of intelligent creation with fairly equal regularity. Children of intermediate age (around nine years of age) preferred creationist arguments to evolutionary arguments. Among the oldest children (around age 12), opinions were fairly evenly split between evolutionist and creationist accounts.

While it is interesting that there was a temporary spike in creationist thinking among nine-year-olds, it is difficult to see how these data strongly support the notion that children, by default, believe in supernatural origins for species. Indeed, the simplest interpretation of the data on the seven-year-olds is that young children have no intuitions regarding where animals come from (this stands in contrast to a wealth of developmental psychological evidence that even infants have a variety of strong intuitions regarding core cognitive domains, as recently reviewed by Spelke and Kinzler [2007]). At the same time, these data do 
not unequivocally support our prediction that children come to adopt beliefs supported by context biases. This may be because each potential answer (creationism, evolution, spontaneous generation) entails a combination of intuitive and counterintuitive concepts. Furthermore, all children in this study shared a single cultural context. This point is particularly salient because even four-year-olds are highly cultural beings. Given that the seven-year-old children in this study were already highly enculturated - most likely having already learned the native language and food preferences of their surrounding culture, for example - and were from the US Midwest, a strongly religious region, they may already have received some explicit religious instruction, yet did not systematically endorse creationism. A stronger test of our predictions would require an examination of animal-origin beliefs among children from different cultural contexts with different prevailing beliefs.

Another study (Evans 2001) ostensibly provides this test, exploring origin beliefs in children from the Midwest who attended either fundamentalist or nonfundamentalist schools. This study replicated the finding that nine-year-old children have a temporary spike in creationist thinking (from more-or-less randomness), leading some to interpret this as evidence for the emergence of religious beliefs in children, independent of cultural context. However, a close look at the methodology and data tell a much more complicated story. It is worth noting that all children in this study were recruited in the same geographical region. In fact, all were from among one of the most strongly religious parts of the United States (the Midwest). Even among the 'non-fundamentalist' group, a full 24 percent of families attended a fundamentalist church. In sum, the children in the different groups did not necessarily come from contexts that differed radically in underlying religious beliefs - a strong test would have to compare, say, a group of atheist Scandinavian children and a group of fundamentalist evangelical children in Alabama. Nonetheless, by age 11, children largely mirrored the beliefs of their parents. This population-difference is noteworthy, as it is suggestive of a strong role for cultural learning in the emergence of creationist beliefs. This is particularly striking because, as already mentioned, nearly a quarter of the 'nonfundamentalist' children in fact attended fundamentalist churches. Among children in a strongly religious region who attended neither fundamentalist schools nor fundamentalist churches, most children nonetheless came to believe in evolution by the time they left the fifth grade. ${ }^{1}$ Although it is possible that the children overcame an innate creationism by effortful indoctrination at school, this account makes the dubious assumption that Midwestern elementary school curricula emphasize and teach evolution to the degree required to overturn a strong default creationist belief. In contrast, recent evidence reveals that, even at the high-school level, most American biology teachers do not adequately teach evolution, and a sizeable minority openly espouse creationism (Berkman and Plutzer 2011).

These results indicate an interesting dynamic in which children's beliefs are substantially shaped by their surrounding cultural milieu (Bering, Blasi and Bjorklund

\footnotetext{
${ }^{1}$ Barrett (2010: 171) cited this very study as demonstrating that 'young children with parents and schools that affirm evolutionary accounts ... still find creationist accounts more attractive.' Other examples of similar claims can be found in the literature.
} 
2005 report a similar pattern). Both findings are consistent with the prediction that - although young children may (or may not) intuitively favor creationist explanations - children's beliefs about the origin of species are substantially influenced by context biases in cultural transmission. Indeed, even spending a short amount of time in a well-designed museum exhibit can lead children to understand evolutionary processes (Evans 2011). In other words, it is possible that people find teleological thinking intuitive and evolutionary thinking comparatively counterintuitive, but it is far from conclusive, given current evidence, that this inevitably (or even strongly probabilistically) pushes people towards creationism. If nothing else, some studies typically cited as supporting such a view do not, as a whole, typify strong tests of the hypothesis that creationist beliefs emerge without cultural scaffolding. Instead, there appears to be a lot of room for context biases in cultural learning to shape people's beliefs about the origins of species, and adults' predominant creationist beliefs (in many parts of the world) may have as much to do with what they are explicitly or implicitly taught in a religious context - and what they are not taught well in an academic context - as with what they find intuitively compelling. We hope that future research will probe deeper into these important questions.

\section{Children's reasoning about death}

Afterlife beliefs have been discussed as another line of evidence suggesting that religious intuitions arise innately without much aid from cultural learning. Around the world, people tend to believe in some form of an afterlife in which people retain their psychological properties after the physical body is dead (Bering 2006). This, then, entails belief in agents with psychological properties, but lacking physical bodies. That is, belief in the afterlife may be a minimally counterintuitive belief that people adopt automatically, without needing context biases to override the unbelievability of this counterintuitive claim. Bering and Bjorklund (2004) investigated children's intuitions about death and the afterlife in a simple series of experiments. They introduced children to a puppet mouse and a puppet crocodile. They emphasized that neither the mouse nor the crocodile were real, but instructed the children to pretend that they were real. In a short play, the crocodile ate the mouse, and the children were told that the mouse 'is not alive anymore.' The experimenters then asked the children a series of questions about the mouse. Some of these questions focused on biological characteristics of the mouse, such as 'Will he ever need to go to the bathroom?' Others focused on psychological traits, such as 'Does he know that he is not alive?' Children reliably reported that normal biological functions ceased after death, but psychological traits persisted. This trend was particularly pronounced among younger children, leading the authors to conclude that children innately believe in an afterlife. This developmental timeline is crucial to the argument. The finding that younger children were more likely to endorse a psychological afterlife than were older children may be taken to indicate that this is an intuitive default cognitive position that is only overridden with time.

Bering (2006) further elaborated this argument, proposing that afterlife beliefs are a naturally selected evolutionary adaptation. In this view, beliefs in an afterlife are the cognitive default; they are present in early childhood. These beliefs are only overridden in later childhood, if at all. Although this account is consistent with 
children's reasoning about the dead mouse, the role of religious enculturation in the formation of afterlife beliefs remains an open question, as several other lines of evidence, taken together, suggest that the matter is far from settled.

Bering's findings contrast starkly with those of Harris and Giminez (2005), who were similarly interested in children's intuitions about death. They described the death of a grandparent, rather than an explicitly fictional mouse, to Catholic children using either religious or secular cues. Unlike Bering and Bjorklund (2004), these authors found that older, rather than younger, children were more likely to endorse a psychological afterlife. This was especially likely when the death was framed in religious terms, implying that children readily (and perhaps initially) adopt a strictly biological conception of death, but that they can successfully recount a religious conception of death, replete with psychological immortality, only after some religious teaching and when the problem is framed in religious terms. In this example, the age difference would indicate that religious enculturation leads to an increase, not a decrease, in afterlife beliefs. In other words, afterlife beliefs may not be the default, but rather a separate narrative style about death that is elaborated through explicit religious teaching.

Astuti and Harris (2008) further probed people's intuitions regarding death. They again asked a series of questions after describing a death in either religious or secular contexts. They compared both adults and children in a village in Madagascar. In this area, both children and adults are regularly exposed to both animal and human deaths. This is a particularly useful test because it is examining beliefs about actual, concrete death, rather than the death of an admittedly fictional mouse puppet (keep in mind the ease with which children can reason about fictional agents without necessarily thinking that they are answering questions about real entities). Adults and older children reliably stated that both physical and mental processes ceased at death, unless asked in a religious context. In a detailed follow-up with only children, the youngest participants (under five years old) did not demonstrate reliable patterns in their conception of death. Older children typically stated that both mental and physical processes ended at death. Taken together, these results pose a serious challenge to the claim that afterlife beliefs represent a default position. On the contrary, they suggest that afterlife beliefs are the reliable products of religious instruction. Children appear able to outline both a biological and a religious conception of death. Both are honed and shaped by the children's surrounding culture over time. One possibility is that afterlife beliefs are only a 'soft' cognitive default that is easily overcome by cultural learning. Alternatively, and consistent with the latter two sets of studies (Astuti and Harris 2008; Harris and Giminez 2005), afterlife beliefs may be the end result of cultural transmission shaped by context biases, and not a cognitive default at all. Either way, the present evidence is consistent with the view that context biases play an important role in the formation of these beliefs.

\section{Atheism²: the cultural transmission of (dis)belief}

Recently this journal published an interesting exchange regarding, among other things, a debate about the implications of atheism for the 'naturalness of religion'

\footnotetext{
${ }^{2} \mathrm{By}$ 'atheism' we mean a disbelief or non-belief in supernatural agents - the lack of theism.
} 
hypothesis (Barrett in press; Bering in press; Geertz and Markússon 2010). According to this hypothesis, some religious concepts emerge naturally, though probabilistically, during development. For example, Boyer (2008: 1039) argues that 'some form of religious thinking seems to be the path of least resistance for our cognitive systems. By contrast, disbelief is generally the result of deliberate, effortful work against our natural cognitive dispositions - hardly the easiest ideology to propagate.' Similarly, Barrett (2004: 108) claims that 'being an atheist is not easy ... As odd as it sounds, it isn't natural to reject all supernatural agents.' Bloom (2007: 148) contrasts the claims of self-described atheists with the view that 'people everywhere naturally have some tacit supernatural beliefs; these arise in children regardless of the culture.' Thus, the naturalness of religion makes atheism appear, in a sense, 'unnatural.' This perspective raises three distinct, but interrelated, possibilities. First, it predicts that atheism should be unusual, only occurring in rare and improbable situations worldwide. Second, it predicts that atheism is only 'skin deep,' and that avowed atheists might retain some implicit theism (e.g., Bering [in press]; see also Slingerland [2008]). Third, even if atheism exists at the implicit level, it might only arise when people reflectively override theistic intuitions (Barrett 2004). We evaluate each of these possibilities below and contrast these strong predictions made by the 'naturalness of religion' hypothesis with a theoretical perspective that incorporates context-biased cultural learning. In this view, atheism can be placed within the 'naturalness of religion' hypothesis as long as the broader cultural context is also taken into account. (See, e.g., Geertz and Markússon [2010] for a similar argument). At this stage, empirical data on the psychology of atheism is scant, so this critical examination is necessarily limited. However, many claims for the etiology of atheism remain untested, and are currently open (and fascinating) empirical questions.

First, is atheism a rare aberration? A substantial and growing proportion of North Americans claim to have no religion (Kosmin and Keysar 2001; Statistics Canada 2003). Around the globe, there is a trend towards secularization likely driven by economic and existential security, although, because of low birthrates of secularized societies, levels of religiosity remain stable in the world overall (Norris and Inglehart 2004). Although measuring the prevalence of atheism in the world is no easy task, in one estimate, more than half of a billion people claim to not believe in God or gods, making nonbelievers the fourth largest 'religious' group in the world today (Zuckerman 2007). Thus a substantial number of people claim to be atheists, even though atheists are among the least trusted groups of people in the world (e.g., Edgell, Gerteis and Hartmann [2006]; Gervais [in press]; Gervais, Shariff and Norenzayan [2010]; Jacoby [2004]).

Second, might all of these people openly espouse atheism while implicitly harboring theistic belief? This possibility is not, in principle, implausible given that experimental psychologists often find divergence between explicit and implicit measures of attitudes (e.g., Nosek [2007]). Furthermore, people often have little or no introspective access into their own mental states that operate outside of conscious awareness, and thus may not be able to accurately report their implicit beliefs in surveys (e.g., Nisbett and Wilson [1977]). Although there is a surprising dearth of research directly examining the beliefs or intuitions of atheists, it is possible to approach the subject indirectly, by examining whether even avowed atheists react similarly to believers when given subtle, implicit experimental religious prods. In one experiment, Dijksterhuis et al. (2008) examined peoples' feelings of 
authorship for events in a computer task. In this task, participants had to identify words as either real or nonsense. When participants responded, the word disappeared. They were told, however, that they were competing against the computer and that sometimes the computer would make the word disappear on its own. When participants were subliminally flashed personal pronouns (' ${ }^{\prime}$ ', 'me') during the task, they felt more personally responsible for the disappearing words than when subliminally flashed the word 'computer.' This indicates that the subliminally flashed word (a 'prime,' in the parlance of experimental psychology) influenced the degree to which participants assigned credit for an action to either themselves or an external agent.

Now to the key experiment. In a follow-up, participants felt less responsible for making the words disappear when primed with 'God' during the task. Importantly, this effect was entirely driven by religious believers. Nonbelievers were unaffected by even subliminal God primes, suggesting that atheists are indeed atheists, even on an implicit level. This result is similar to one other priming study in which implicit God primes increased generosity among believers but had no effect on nonbelievers (Shariff and Norenzayan 2007: Study 2); similarly, across four studies, God primes increased perceived social surveillance among believers, but did not reliably affect nonbelievers (Gervais and Norenzayan in press). To the extent that atheists are uninfluenced by implicit religious primes, we can conclude that cultural learning of religion, which is absent among at least some atheists who were never exposed to religion, plays a role in religious beliefs. However, several other religious-priming studies have found similar responsiveness by believers and nonbelievers (e.g., Pichon, Boccato and Saroglou [2007]; Randolph-Seng and Nielsen [2007]; Shariff and Norenzayan [2007]: Study 1). Thus, the available literature is inconclusive regarding when, and why, explicitly nonreligious individuals might be influenced by unconscious reminders of religion, and a number of potential explanations (including, but not limited to, the putative existence of implicit theism) for these inconsistencies are available (see Norenzayan, Shariff and Gervais [2010] for a more detailed discussion). Further progress on this question requires, for example, that researchers compare atheists who grew up in largely religious contexts and subsequently abandoned faith (atheist converts) to atheists who grew up in nonreligious contexts (lifetime atheists) in order to conclusively determine the relative contribution of cultural learning to religious disbelief. Therefore, the claim that atheism in general is only skin deep is an intriguing hypothesis that currently remains largely untested and poorly investigated. This fascinating and open area deserves more direct research in the future.

Finally, is atheism more cognitively effortful than belief? If religion arises naturally, then atheists might be able to sustain their disbelief only through the continual exertion of cognitive effort, in the same way that physicists can study subatomic particles through the continual exertion of cognitive effort to override natural, yet faulty, intuitions about the world. This claim has not to date been rigorously tested, but available circumstantial evidence indicates that atheism might not be effortful among individuals who were never exposed to context-based cues that one should adopt religious belief. Zuckerman (2008) investigated the role of religion in Denmark and Sweden, two of the most atheistic countries in the world. Zuckerman was impressed, above all, by the banality of Scandinavian disbelief. These people were not atheists because of Herculean efforts to control their latent belief. Rather, they were raised in a culture in which disbelief was commonplace, and 
in which few people displayed religious CREDs. At the same time, some of our own experimental research indicates that analytic reasoning reduces religious belief (Gervais and Norenzayan 2010). Although this finding may also be taken to support the notion that atheism requires cognitive effort, the chain of logic for this latter assertion is unclear. Just because effortful analytic reasoning reduces religious belief, it does not follow that all religious disbelievers must use cognitive effort to maintain their atheism (although some might). ${ }^{3}$ This is because there likely are multiple psychological paths to atheism, including both cognitively effortful religious deconversion and simply growing in the absence of contextbased cues supporting supernatural-agent beliefs. Nonetheless, much more research is needed to determine the role of cognitive effort in atheism.

According to the view that religious beliefs are exclusively produced by intuitions and content biases, atheism is unnatural and improbable. On the other hand, a view that incorporates context biases predicts that both religious beliefs and atheism are 'natural,' in the sense that they are products of different cultural contexts. (For a complementary perspective, see Geertz and Markússon [2010]). If a learner grows up around religious models, he is likely to become religious. If, on the other hand, a learner who grows up around people who do not hold religious beliefs- or people who do not exhibit credibility-enhancing displays of their underlying religious beliefs - will come to not hold religious beliefs, even if some natural intuitions, however weakly or strongly, might enable people to easily mentally represent supernatural agents.

Lanman (2009; submitted) studied the role of credibility-enhancing displays of religious conviction in the decline of religiosity in Scandinavia. The results were consistent with the framework proposed in the present paper. Even among children raised by parents who themselves believed in God, kids who did not see credibilityenhancing displays of their parents' faith (by, for example, observing them engage in religious rituals), grew up to be nonbelievers. Consistent with this account, analysis of raw World Values Survey data (downloaded 5 February 2011, from www.worldvalues.org) from 86209 individuals worldwide, reveals that of people who report that they had an explicitly religious upbringing, 84 percent become explicitly religious; in contrast, of people raised without religion, fewer than half become explicitly religious. In other words, while some forms of disbelief may involve effortful overriding of intuitive theistic beliefs, as has been argued before (e.g., Barrett [2004]; Bloom [2007]; Gervais and Norenzayan [2010]), other forms of atheism may arise because people simply did not have cultural support for theistic belief, and subsequently never developed belief in the first place. Religious belief is the natural product of cultural contexts in which learners receive clear cues that their models hold religious belief; atheism naturally results from contexts in which these cues are absent.

Context biases can also explain another puzzling aspect of religion: most people are atheists when it comes to most of the supernatural agents about which they have ever heard (Dawkins 2006). If content biases are sufficient to explain belief, then how do people only come to believe in the 'right' gods (as usually judged

\footnotetext{
${ }^{3}$ In this regard, atheism (and, perhaps, faith) might be like golf. If you start playing when you are five, you develop a natural swing and don't have to think about it. If you start playing when you are 25, a proper swing remains cognitively effortful!
} 
by their surrounding culture)? Why do Christians not believe in Zeus or Shiva? Although this selective belief is unexplainable by content biases alone, it is easily explainable if context biases determine the gods in which people come to believe or disbelieve. Finally, context biases may also explain patterns in belief in some supernatural agents across the lifespan. For many children, Santa Claus is a real, morally concerned supernatural agent who wields the power to dispense either gifts or coal as just desserts for good and bad behavior, respectively. As children age, they gradually come to disbelieve in Santa Claus, even though Santa's cognitive content remains the same. Context changes, however, and as children age, they stop witnessing credibility-enhancing displays of others' faith in Santa. As a result, Santa Claus is a god to children, but an entertaining folktale (and useful tool) for many adults. (See Gervais and Henrich [2010] for further discussion of these related points about Zeus and Santa).

\section{Moving forward}

The cognitive science of religion has anchored the study of religion in up-to-date scientific explanations of human cognitive architecture (Boyer 2003). This perspective also has effectively fulfilled the promise of 'naturalizing religion,' that is, offering a viable program of research that can demonstrate, step by step, how well-understood natural cognitive predispositions statistically shape and constrain the mental representation and cultural distribution of religious beliefs and behaviors in populations of minds. We propose that the content biases that have been the foci of this approach, such as the mnemonic advantage enjoyed by minimally counterintuitive concepts, are necessary but insufficient to explain religious beliefs and commitments. These content biases render some concepts successful because they are inherently attention-grabbing and memorable. However, we suspect that children and adults, who are equipped with cognitive abilities for epistemic vigilance and skepticism, are less likely to actually believe in counterintuitive concepts. This presents a dilemma for the current cognitive approaches to religion that focus solely on content biases. To gain a more complete understanding of the predictable recurrence - and occasional absence - of religious faith throughout history and across cultures, researchers must incorporate both content and context biases in cultural learning into the cognitive science of religion. In this view, people may find a minimally counterintuitive concept memorable (such as in fairytales), but they only come to believe in - and commit to - the counterintuitive concepts supported by context biases. (See also Bergstrom et al. [2006]; Harris and Koenig [2006]). In particular, people should come to believe in counterintuitive concepts that most other people believe in (e.g., Henrich and Boyd [1998]), those that successful, prestigious individuals believe in (e.g., Henrich and Gil-White [2001]), or those to which people make credibility-enhancing displays of their own commitment (Henrich 2009). Among other things, religion is a suite of socially acquired beliefs. (See also Beit-Hallahmi and Argyle [1997]). In the present paper, we proposed a theoretical framework that also anchors the cognitive science of religion in up-to-date scientific explanations of cultural transmission and evolution, with the goal of further advancing the evolutionary study of religion.

A cultural-learning approach illuminates a number of phenomena, including the development of children's beliefs about both the origins of animals and the afterlife, and, especially, the cultural prevalence of religious disbelief and the psychological 
processes underlying atheism. That said, there is remarkably little experimental evidence focused on the causes and consequences of religious belief and disbelief, meaning that the state of the field precludes, for now, the drawing of strong conclusions regarding a wide range of important questions. Nonetheless, an integrated framework devoted to understanding both the cognitive biases that shape the content of religious beliefs, and also the cultural learning biases that influence the degree of commitment to particular religious beliefs or lack thereof, promises, if nothing else, to clarify theory regarding the role of cultural learning in religious belief, highlight a number of as-yet-untested hypotheses, and present a fruitful program for future research.

Will M. Gervais is a Social Psychology PhD candidate at the University of British Columbia. Broadly, Will studies how cognition, evolution, and culture interact to shape people's beliefs about the world. Will's research draws upon a wide variety of subfields within psychology, including social cognition, prejudice/stereotyping, reasoning, evolutionary psychology, and cultural psychology. This research program also informs basic theory on classic social psychological topics including the nature of prejudice, the role of intuition and analytic processing in reasoning about the world, and the ways that awareness of other social agents can affect cognition and behavior. He grew up in a small town in the mountains of Colorado.

Aiyana K. Willard is a PhD student working in the department of psychology at the University of British Columbia. She is interested in the cognitive and cultural origins of religious cognition and religious belief, as well as the origins of culture in human evolution more generally. Her research primarily looks at how cognitive biases mix with cultural contexts to explain the universal and culturally idiosyncratic features of religious behavior in human cultures.

Ara Norenzayan is Associate Professor of Psychology at the University of British Columbia, Vancouver. His areas of research include evolutionary and cognitive explanations of religious thought and behavior, issues of cultural variability and universality in human psychology, and relations between culture and evolution. Prior to UBC, he was a postdoctoral fellow at the Centre de Recherche en Épistemologie Appliquée (CREA), École Polytechnique, Paris, after which he served on the faculty of the University of Illinois, Urbana-Champaign. He is the author of more than 50 articles and book chapters, and the co-editor of Evolution, Culture, and the Human Mind, a volume that synthesizes evolutionary and cultural approaches to psychology. His upcoming book is on the evolutionary origins of prosocial religions, and is titled, The Making of Big Gods.

Dr. Henrich holds the Canada Research Chair in Culture, Cognition and Coevolution at the University of British Columbia, where he is appointed in both Economics and Psychology. His theoretical work focuses on how natural selection has shaped human learning and how this in turn influences cultural evolution, and culturegene coevolution. Methodologically, his research synthesizes experimental and analytical tools drawn from behavioural economics and psychology with indepth quantitative ethnography, and has performed long-term fieldwork in the Peruvian Amazon, rural Chile, and in Fiji. Trained and granted tenure in anthropology, his work has been published in the top journals in biology, psychology, 
anthropology and economics, including Science, Nature, PNAS, Behavioral and Brain Sciences, American Economic Review, Current Anthropology and Trends in Cognitive Science. In 2004 he was awarded the Presidential Early Career Award, the highest award bestowed by the United States upon scientists early in their careers. In 2007 he coauthored Why Humans Cooperate. In 2009 the Human Behavior and Evolution Society awarded him their Early Career Award for Distinguished Scientific Contributions. He is currently a fellow at the Canadian Institute for Advanced Research.

\section{References}

Astuti, R., P.L. Harris. 2008. Understanding Mortality and the Life of the Ancestors in Rural Madagascar. Cognitive Science 32: 713-740.

Atran, S. 2002. In Gods We Trust: The Evolutionary Landscape of Religion. Oxford: Oxford University Press. Atran, S., J. Henrich. 2010. The Evolution of Religion: How Cognitive By-products, Adaptive Learning Heuristics, Ritual Displays, and Group Competition Generate Deep Commitments to Prosocial Religions. Biological Theory: Integrating Development, Evolution, and Cognition 5: 18-30.

Atran, S., A. Norenzayan. 2004. Religion's Evolutionary Landscape: Counterintuition, Commitment, Compassion, Communion. Behavioral and Brain Sciences 27: 713-770.

Banerjee, R., N. Yuill, C. Larson, K. Easton, E. Robinson, M. Rowley. 2007. Children's Differentiation between Beliefs about Matters of Fact and Matters of Opinion. Developmental Psychology 43: 1084-1096.

Barrett, J.L. 2000. Exploring the Natural Foundations of Religious Belief. Trends in Cognitive Science 4: 29-34.

2004. Why Would Anyone Believe in God? Walnut Creek, CA: AltaMira Press.

- 2008. Why Santa Claus Is Not a God. Journal of Cognition and Culture 8: 149-161.

- In press. The Relative Unnaturalness of Atheism: On Why Geertz and Markusson Are Both Right and Wrong. Religion.

Barrett, J.L., M.A. Nyhof. 2001. Spreading Nonnatural Concepts: The Role of Intuitive Conceptual Structures in Memory and Transmission of Cultural Materials. Journal of Cognition and Culture 1: 69-100.

Barrett, J. L. 2010. The Relative Unnaturalness of Atheism: On Why Geertz and Marküsson Are Both Right and Wrong. Religion 40, 169-172.

Beit-Hallahmi, B., M. Argyle. 1997. The Psychology of Religious Behaviour, Belief and Experience. London: Routledge.

Bergstrom, B., B. Moehlmann, P. Boyer. 2006. Extending the Testimony Problem: Evaluating the Truth, Scope and Source of Cultural Information. Child Development 77: 531-538.

Bering, J.M. 2006. The Folk Psychology of Souls. Behavioral and Brain Sciences 29: 453-498.

— 2011. In press. Atheism Is Only Skin Deep: Geertz and Markusson Rely Mistakenly on Sociodemographic Data as Meaningful Indicators of Underlying Cognition. Religion.

Bering, J.M., D.F. Bjorklund. 2004. The Natural Emergence of Reasoning about the Afterlife as a Developmental Regularity. Developmental Psychology 40: 217-233.

Bering, J.M., C.H. Blasi, D.F. Bjorklund. 2005. The Development of 'Afterlife' Beliefs in Religiously and Secularly Schooled Children. British Journal of Developmental Psychology 23: 587-607.

Berkman, M.B., E. Plutzer. 2011. Defeating Creationism in the Courtroom, but Not in the Classroom. Science 331: 404-405.

Birch, S.J.A., N. Akmal, K.L. Frampton. In press. Two-year-olds Are Vigilant of Others' Nonverbal Cues to Credibility. Developmental Science.

Birch, S. A. J., Vauthier, S. A., Bloom, P. 2008. Three- and four-year-olds spontaneously use others' past performance to guide their learning. Cognition, 107, 1018-1034.

Bloom, P. 2007. Religion Is Natural. Developmental Science 10: 147-151.

Bloom, P., D.S. Weisberg. 2007. Childhood Origins of Adult Resistance to Science. Science 316: $996-997$. Boyd, R., P.J. Richerson. 1985. Culture and the Evolutionary Process. Chicago, IL: University of Chicago Press.

Boyer, P. 2001. Religion Explained: The Evolutionary Origins of Religious Thought. New York: Basic Books. Boyer, P., C. Ramble. 2001. Cognitive Templates for Religious Concepts: Cross-cultural Evidence for Recall of Counter-intuitive Representations. Cognitive Science 25: 535-564. 
Boyer, P. 2003. Religious Thought and Behaviour as By-products of Brain Function. Trends in Cognitive Sciences 7, 119-124.

Boyer, P., P. Lienard. 2006. Why Ritualized Behavior? Precaution Systems and Action-parsing in Developmental, Pathological and Cultural Rituals. Behavioral and Brain Sciences 29: 1-56.

Bulbulia, J. 2008. Meme Infection or Religious Niche Construction? An Adaptationist Alternative to the Cultural Maladaptationist Hypothesis. Method and Theory in the Study of Religion 20: 67-107.

Chudek, M., S. Heller, S. Birch, J. Henrich. 2010. Prestige-biased Cultural Learning: Developmental Evidence for Selective Cultural Learning Based on Differential Bystander Attention to Models. Unpublished manuscript under review

Dawkins, R. 2006. The God Delusion. New York: Houghton Mifflin Harcourt.

Dijksterhuis, A., J. Preston, D.M. Wegner, H. Aarts. 2008. Effects of Subliminal Priming of Self and God on Self-attribution of Authorship for Events. Journal of Experimental Social Psychology 44: 2-9.

DiLalla, L.F., M.W. Watson. 1988. Differentiation of Fantasy and Reality: Preschoolers' Reactions to Interruptions in Their Play. Developmental Psychology 24: 286-291.

Donald, M. 2001. A Mind so Rare: The Evolution of Human Consciousness. New York: Norton.

Edgell, P., J. Gerteis, D. Hartmann. 2006. Atheists As "Other": Moral Boundaries and Cultural Membership in American Society. American Sociological Review 71: 211-234.

Evans, E.M. 2000. The Emergence of Beliefs about the Origins of Species in School-age Children. MerrillPalmer Quarterly: A Journal of Developmental Psychology 46: 221-254.

- 2001. Cognitive and Contextual Factors in the Emergence of Diverse Belief Systems Creationism: Versus Evolution. Cognitive Psychology 42: 217-266.

- 2011. What Is Creationism and How Do You Catch It? Paper presented at the Psychology of Religion and Spirituality preconference at the annual meeting of the Society for Personality and Social Psychology, San Antonio, TX, January.

Foster, K., H. Kokko. 2009. The Evolution of Superstitious and Superstition-like Behaviour. Proceedings of the Royal Society of London B 276: 31-37.

Geertz, A.W., G.I. Markússon. 2010. Religion Is Natural, Atheism Is Not: On Why Everybody Is Both Right and Wrong. Religion 40: 152-165.

Gervais, W.M. In press. Finding the Faithless: Perceived Atheist Prevalence Reduces Anti-atheist Prejudice. Personality and Social Psychology Bulletin.

Gervais, W.M., J. Henrich. 2010. The Zeus Problem: Why Representational Content Biases Cannot Explain Faith in Gods. Journal of Cognition and Culture 10: 383-389.

Gervais, W.M., A. Norenzayan. 2010. Analytical Reasoning Reduces Religious Belief. Unpublished manuscript under review

Gervais, W.M., A. Norenzayan. In press. Like a Camera in the Sky? Thinking about God Increases Public Self-awareness and Socially Desirable responding. Journal of Experimental Social Psychology.

Gervais, W.M., A.F. Shariff, A. Norenzayan. 2010. Do You Believe in Atheists? Distrust Is Central to Anti-atheist Prejudice. Unpublished manuscript under review

Golomb, C., L. Galasso. 1995. Make Believe and Reality: Explorations of the Imaginary Realm. Developmental Psychology 31: 800-810.

Golumb, C., R. Kuersten. 1996. On the Transition From Pretense Play to Reality: What Are the Rules of the Game? British Journal of Developmental Psychology 14: 203-217.

Guthrie, S.G. 1993. Faces in the Clouds: A New Theory of Religion. New York: Oxford University Press.

Harris, P.L., E. Brown, C. Marriott, S. Whittall, S. Harmer. 1991. Monsters, Ghosts and Witches: Testing the Limits of the Fantasy-reality Distinction in Young Children. British Journal of Developmental Psychology 9: 105-123.

Harris, P.L., M. Gimenez. 2005. Children's Acceptance of Conflicting Testimony: The Case of Death. Journal of Cognition and Culture 5: 143-164.

Harris, P.L., M.A. Koenig. 2006. Trust in Testimony: How Children Learn about Science and Religion. Child Development 77: 505-524.

Harris, P.L., E.S. Pasquini, S. Duke, J.J. Asscher, F. Pons. 2006. Germs and Angels: The Role of Testimony in Young Children's Ontology. Developmental Science 9: 76-96.

Henrich, J. 2009. The Evolution of Costly Displays, Cooperation, and Religion: Credibility Enhancing Displays and Their Implications for Cultural Evolution. Evolution and Human Behaviour 30: 244-260.

Henrich, J., R. Boyd. 1998. The Evolution of Conformist Transmission and the Emergence of Betweengroup Differences. Evolution and Human Behavior 19: 215-242.

Henrich, J., F. Gil-White. 2001. The Evolution of Prestige: Freely Conferred Deference as a Mechanism for Enhancing the Benefits of Cultural Transmission. Evolution and Human Behavior 22: 165-196. 
Henrich, J., R. McElreath. 2003. The Evolution of Cultural Evolution. Evolutionary Anthropology 12: 123-135.

Heyman, G.D. 2008. Children's Critical Thinking When Learning from Others. Current Directions in Psychological Science 17: 344-347.

Heyman, G.D., C.H. Legare. 2005. Children's Evaluation of Sources of Information about Traits. Developmental Psychology 41: 636-647.

Jacoby, S. 2004. Freethinkers: A History of American Secularism. New York: Metropolitan.

Jaswal, V. K., Neely, L. A. 2007. Adults don't always know best: Preschoolers use past reliability over age when learning new words. Psychological Science 17, 757-758.

Kelemen, D. 2004. Are Children 'Intuitive Theists'? Psychological Science 15: 295-301.

Kendal, J., L. Giraldaeu, K. Laland. 2009. The Evolution of Social Learning Rules: Payoff-biased and Frequency-dependent Biased Transmission. Journal of Theoretical Biology 260: 210-219.

Koenig, M. A., F. Clément, P. L. Harris. 2004. Trust in Testimony: Children's Use of True and False Statements. Psychological Science 15, 694-698.

Koenig, M.A., P.L. Harris. 2005. Preschoolers Mistrust Ignorant and Inaccurate Speakers. Child Development 76: 1261-1277.

Kirkpatrick, L. 1999. Toward an Evolutionary Psychology of Religion. Journal of Personality 67: 921-952.

Kosmin, B.A., A. Keysar. 2008. American Religious Identification Survey Summary Report. Trinity College, Hartford, CT. http://www.americanreligionsurvey-aris.org/reports/ARIS_Report_2008.pdf

Kosmin, B.A., A. Keysar, 2008. American Religious Identification Survey Summary Report. Trinity College, Hartford, CT. Retrieved June 3, 2009, from http://www.americanreligionsurvey-aris.org/ reports/ARIS_Report_2008.pdf.

Lanman, J. 2009. Towards a Cognitive Anthropology of Secularization. Paper presented at Society for the Scientific Study of Religion, Denver, CO.

- Submitted. A Secular Mind: Towards a Cognitive Anthropology of Non-theism. Oxford: Oxford University Press.

McCauley, R.N. 2000. The Naturalness of Religion and the Unnaturalness of Science. In Explanation and Cognition, eds. F.C. Keil and R.A. Wilson. Cambridge, MA: MIT Press, 61-86.

McCauley, R. N., E. Cohen. 2010. Cognitive science and the naturalness of religion. Philosophy Compass 5, 779-792.

McCloskey, M., A. Caramazza, B. Green. 1980. Curvilinear motion in the absence of external forces: naive beliefs about the motion of objects. Science 210, 1139-1141.

Mead, M. 1932. The Changing Culture of an Indian Tribe. Columbia University Contributions to Anthropology 15: 1-313.

Morison, P., H. Gardener. 1978. Dragons and Dinosaurs: The Child's Capacity to Differentiate Fantasy from Reality. Child Development 49: 642-648.

Nisbett, R. E., Wilson, T. 1977. Telling more than we can know: Verbal reports on mental processes. Psychological Review 84, 231-259.

Norenzayan, A., W. Gervais. In press. The Cultural Evolution of Religion. In Creating Concilience: Integrating Science and the Humanities, eds. E. Slingerland and M. Collard. Oxford: Oxford University Press.

Norenzayan, A., S. Atran, J. Faulkner, M. Schaller. 2006. Memory and Mystery: The Cultural Selection of Minimally Counterintuitive Narratives. Cognitive Science 30: 531-553.

Norenzayan, A., A.F. Shariff, W.M. Gervais. 2010. The Evolution of Religious Misbelief. Behavior and Brain Sciences 32: 531-532.

Norris, P., R. Inglehart. 2004. Sacred and Secular: Religion and Politics Worldwide. Cambridge: Cambridge University Press.

Nosek, B.A. 2007. Explicit-Implicit Relations. Current Directions in Psychological Science 16: 65-69.

Pasquini, E.S., K. Corriveau, M. Koenig, P.L. Harris. 2007. Preschoolers Monitor the Relative Accuracy of Informants. Developmental Psychology 43: 1216-1226.

Pichon, I., G. Boccato, V. Saroglou. 2007. Nonconscious Influences of Religion on Prosociality: A Priming Study. European Journal of Social Psychology 37: 1032-1045.

Pyysiäinen, I. 2001. How Religion Works. Boston, MA, Leiden, NL: Brill.

Pyysiäinen, I., V. Antonnen, eds. 2002. Current Approaches in the Cognitive Science of Religion. New York: Continuum.

Pyysiäinen, I., Hauser, M. 2010. The Origins of Religion: Evolved Adaptation or By-product? Trends in Cognitive Sciences 14, 104-109.

Randolph-Seng, B., M.E. Nielsen. 2007. Honesty: One Effect of Primed Religious Representations. The International Journal for the Psychology of Religion 17: 303-15. 
Richerson, P.J., R. Boyd. 2005. Not By Genes Alone: How Culture Transformed Human Evolution. Chicago: University of Chicago Press.

Sabbagh, M.A., D.A. Baldwin. 2001. Learning Words from Knowledgeable Versus Ignorant Speakers: Links Between Preschoolers' Theory of Mind and Semantic Development. Child Development 72: 1054-1070.

Samuels, A., M. Taylor. 1994. Children's Ability to Distinguish Fantasy Events from Real-life Events. British Journal of Developmental Psychology 12: 417-427.

Schaller, M., A. Norenzayan, S.J. Heine, T. Yamagishi, T. Kameda. 2010. Evolution, Culture, and the Human Mind. London: Psychology Press.

Shariff, A.F., A. Norenzayan. 2007. God Is Watching You: God Concepts Increase Prosocial Behavior in an Anonymous Economic Game. Psychological Science 18: 803-809.

Sharon, T., J.D. Wooley. 2004. Do Monsters Dream? Young Children's Understanding of the Fantasy/ reality Distinction. British Journal of Developmental Psychology 22: 293-310.

Skolnik, D., P. Bloom. 2006. What Does Batman Think about SpongeBob? Children's Understanding of the Fantasy/fantasy Distinction. Cognition 101: B9-B18.

Slingerland, E. 2008. What Science Offers the Humanities: Integrating Body and Mind. Cambridge: Cambridge University Press.

Sosis, R., C. Alcorta. 2003. Signaling, Solidarity, and the Sacred: The Evolution of Religious Behavior. Evolutionary Anthropology 12: 264-274.

Spelke, E.S., K.D. Kinzler. 2007. Core Knowledge. Developmental Science 10: 89-96.

Sperber, D. 1996. Explaining Culture: A Naturalistic Approach. Oxford, UK: Blackwell.

Sperber, D., F. Clement, O.M. Heintz, H. Mercier, G. Origgi, D. Wilson. 2010. Epistemic Vigilance. Mind and Language 25: 359-393.

Statistics Canada. 2003. 2001 Census: Analysis Series. Religions in Canada, by Canada, Statistics. Ottawa. http://www12.statcan.ca/english/census01/Products/Analytic/companion/rel/pdf/96F0030 XIE2001015.pdf

Taylor, M. 1999. Imaginary Companions and the Children Who Create Them. New York: Oxford University Press.

Tomasello, M. 1999. The Cultural Origins of Human Cognition. Cambridge, MA: Harvard University Press. Wade, N. 2009. The Faith Instinct: How Religion Evolved and Why It Endures. New York: Penguin Press. Whiten, A. 2005. The Second Inheritance System of Chimpanzees and Humans. Nature 437: 52-55.

Willard, A., A. Norenzayan, W.M. Gervais, J. Henrich. 2010. Minimally Counterintuitive Concepts are Unbelievable. Unpublished raw data, Vancouver, Canada

Wilson, D. S. 2003. Darwin's Cathedral: Evolution, Religion, and the Nature of Society. Chicago: University of Chicago Press.

Woolley, J.D., H.M. Wellman. 1990. Young Children's Understanding of Realities, Nonrealities, and Appearances. Child Development 61: 946-961.

Zuckerman, P. 2007. Atheism: Contemporary Numbers and Patterns. In The Cambridge Companion to Atheism, eds. M. Martin. Cambridge, UK: Cambridge University Press, 47-65.

. 2008. Society Without God: What the Least Religious Nations Can Tell Us about Contentment. New York: New York University Press. 